\title{
Palonosetron Prevents Highly Emetogenic Chemotherapy- induced Nausea and Vomiting in Oral Cancer Patients
}

\author{
SHINYA SENTO ${ }^{1}$, NAOYA KITAMURA ${ }^{1}$, TETSUYA YAMAMOTO ${ }^{1}$, KOICHI NAKASHIRO $^{2}$, \\ HIROYUKI HAMAKAWA ${ }^{2}$, SOICHIRO IBARAGI ${ }^{3}$, AKIRA SASAKI $^{3}$, NATSUMI TAKAMARU ${ }^{4}$, \\ YOJI MIYAMOTO ${ }^{4}$, ISAMU KODANI ${ }^{5}$, KAZUO RYOKE $^{5}$, KATSUAKI MISHIMA ${ }^{6}$, \\ YOSHIYA UEYAMA ${ }^{6}$ and ORAL CANCER STUDY GROUP OF CHUGOKU-SHIKOKU
}

\author{
${ }^{1}$ Department of Oral and Maxillofacial Surgery, Kochi Medical School, Kochi University, Nankoku, Japan; \\ ${ }^{2}$ Department of Oral and Maxillofacial Surgery, Ehime University Graduate School of Medicine, Toon, Japan; \\ ${ }^{3}$ Department of Oral and Maxillofacial Surgery, Okayama University Graduate School of Medicine, \\ Dentistry and Pharmaceutical Sciences, Okayama, Japan; \\ ${ }^{4}$ Department of Oral Surgery, Subdivision of Molecular Oral Medicine, \\ Division of Integrated Sciences of Translational Research, Institute of Biomedical Sciences, \\ Tokushima University Graduate School, Tokushima, Japan; \\ ${ }^{5}$ Division of Oral and Maxillofacial Biopathological Surgery, Department of Medicine of Sensory and Motor Organs, \\ School of Medicine, Tottori University Faculty of Medicine, Yonago, Japan; \\ ${ }^{6}$ Department of Oral and Maxillofacial Surgery, Graduate School of Medicine, \\ Yamaguchi University, Yamaguchi, Japan
}

\begin{abstract}
Background/Aim: To evaluate the efficacy of palonosetron in preventing acute and delayed nausea and vomiting in patients receiving highly emetogenic chemotherapy (HEC) in oral cancer patients. Patients and Methods: Oral cancer patients receiving HEC were enrolled; among the 40 patients, 87 courses of chemotherapy were administered. On day $1,0.75 \mathrm{mg}$ palonosetron was intravenously administrated just before chemotherapy. Results: The primary endpoint was the proportion of patients with a complete response $(C R)$ and the secondary endpoint was the proportion of patients with complete control $(C C)$ during the acute and delayed phase. During the acute phase, 86 of 87 courses (98.9\%) had CR and 84 of 87 courses (96.6\%) had CC. During the delayed phase, 84 of 87 courses (96.6\%) had CR and 70 of 87 courses (80.5\%) had CC. Conclusion: Palonosetron is effective at preventing HECinduced chemotherapy-induced nausea and vomiting (CINV) in oral cancer chemotherapeutic regimens in the acute and delayed phases.
\end{abstract}

Correspondence to: Shinya Sento, Department of Oral and Maxillofacial Surgery, Kochi Medical School, Kochi University, Kohasu, Oko cho, Nankoku-city, Kochi 783 8505, Japan. Tel: +81 888802423, e-mail: shinya-sento@kochi-u.ac.jp

Key Words: Chemotherapy, nausea, vomiting, antiemetic therapy, oral cancer, palonosetron.
The number of cancer-related deaths in Japan is gradually increasing, and reached 368,103 for all cancer types in 2014 . Head and neck cancers, including oral cavity and pharyngeal cancer, accounted for 7,415 of these deaths (1). Although $90 \%$ or more early-stage cancers (stage I-II) can be cured using surgical or radiation monotherapy, such a high survival rate cannot be expected in advanced cancers (stage III-IV) (2). Multidisciplinary therapy of surgery, chemotherapy, and radiotherapy is widely applied to improve the survival rate of advanced head and neck cancers. In chemotherapy, various regimens, mainly cisplatin (CDDP) combined with docetaxel (DTX) and 5-fluorouracil (5-FU), have been clinically applied and are associated with a high response rate (3). In addition, with the use of a combination of surgery and chemo-radiotherapy, it has become possible to preserve oral function and morphology in highly progressive cases that were thought to be inoperable or in which surgery would result in significant functional impairment. However, chemotherapeutic drugs have a variety of adverse effects, such as fatigue, hair loss, lack of appetite, and nausea. Among these adverse effects, powerful nausea and vomiting often degrade the patient's quality of life (QOL).

The Multinational Association of Supportive Care in Cancer/European Society for Medical Oncology (MASCC/ ESMO) antiemetic guidelines of 2016 categorized CDDPcontaining chemotherapeutic regimens as highly emetogenic chemotherapy (HEC) (4). In recent years, a new category of antiemetic drug has shown effectiveness in the treatment of 
delayed nausea and vomiting. Among them, palonosetron, a second-generation 5-hydroxytryptamine 3 (5-HT3)-receptor antagonist, has attracted attention for its effectiveness in nausea and vomiting, not only in the acute phase but also in the late phase (5), and it is widely used worldwide. Palonosetron has a strong binding affinity and long half-life (6), and has been used for preventing chemotherapy-induced nausea and vomiting (CINV) in patients receiving HEC. Although palonosetron is a highly promising treatment, there have been few reports focusing on chemotherapy regimens for oral cancers, and there are insufficient data regarding its anticipated effects on chemotherapy regimens frequently used in oral cancers. In this study, we evaluated the effectiveness of palonosetron on CINV in chemotherapeutic regimens for oral cancers.

\section{Patients and Methods}

Patients and study design. Forty oral cancer patients who were receiving HEC (including CDDP) were enrolled into a single-arm study conducted at 6 facilities in Japan between November 2011 and April 2016. Before starting chemotherapy or a combined chemoradiation therapy course on day 1 , we administered an antiemetic treatment regimen, including $0.75 \mathrm{mg}$ palonosetron. In addition to the anticancer drug therapy, antiemetic therapy was administered for the necessary number of courses. The start of palonosetron administration was regarded as the first course of chemotherapy. For circumstances other than the above, the protocol treatment was not prescribed, but was administered according to the treatment policy of each facility. The presence or absence and degree of nausea/vomiting from the first course up to the fourth course were investigated using the MASCC Anti-emesis Tool (MAT). MAT is a questionnaire that evaluates nausea/vomiting resulting from chemotherapy.

The major inclusion criteria were as follows: patients who did not experience nausea or vomiting before chemotherapy and patients with an Eastern Cooperative Oncology Group (ECOG) performance status score of $<3$. The major exclusion criteria were as follows: clinical conditions that may cause nausea and vomiting, irrespective of chemotherapy administration, severe organ dysfunction, a history of hypersensitivity to 5-HT3 receptor antagonists and dexamethasone, and a history of a severe drug allergy above grade 3, according to the Common Terminology Criteria for Adverse Events (CTCAE) ver. 4.0.

The study protocol was approved by the ethics committee at each facility. All patients provided written informed consent before participation.

Antiemetic therapy and assessment. In all courses, $0.75 \mathrm{mg}$ of palonosetron was intravenously administered over $30 \mathrm{~min}$ before chemotherapy was commenced. In addition, in most courses, aprepitant (150 mg intravenously on day 1) and dexamethasone (9.9 $\mathrm{mg}$ orally on day 1 and $6.6 \mathrm{mg}$ orally on days 2-4) were administered. Patients were not allowed to take other antiemetic drugs as long as there were no CINV symptoms within $120 \mathrm{~h}$ after palonosetron administration. We defined the periods from the start of palonosetron administration $(0 \mathrm{~h})$ to $120 \mathrm{~h}, 0-24 \mathrm{~h}$, and 24-120 h as the overall, acute, and delayed phases, respectively. When
Table I. Patient characteristics $(n=40)$.

\begin{tabular}{lc}
\hline Age & \\
Mean \pm SD & $66.2 \pm 11.7$ years \\
Minimum - Maximum & $39-89$ years \\
Gender & $26(65 \%)$ \\
Male & $14(35 \%)$ \\
Female & \\
Primary tumor sites & $17(42.5 \%)$ \\
Tongue & $10(25 \%)$ \\
Gingiva & $4(10 \%)$ \\
Buccal mucosa & $4(10 \%)$ \\
Floor of the mouth & $4(10 \%)$ \\
Intraosseous & $1(2.5 \%)$ \\
Maxillary sinus & $39(97.5 \%)$ \\
Histopathological types & $1(2.5 \%)$ \\
Squamous cell carcinoma & \\
Malignant melanoma & \\
\hline
\end{tabular}

breakthrough nausea or emesis occurred despite prophylaxis, rescue medication was allowed at the request of the patient. The treating physicians determined the type of rescue antiemetics.

The primary endpoint was the proportion of patients with a complete response (CR: defined as mild nausea, but no vomiting and no rescue medication) and the secondary endpoint was the proportion of patients with complete control (CC: defined as no vomiting, no rescue medication, and no more than mild nausea) during the acute and delayed phases.

\section{Results}

Patients and chemotherapeutic regimens. The effectiveness of palonosetron on CINV was assessed in a total of 87 courses. Table I shows the patients' characteristics. The mean age of the patients was $66.2 \pm 11.7$ years (range $=39-89$ years), with men accounting for $65 \%$ of the patient population. The tongue was the most common site of primary tumor $(17 / 40$, $42.5 \%)$, followed by the gingiva $(10 / 40,25 \%)$. Squamous cell carcinoma was the most common histopathological type (39/40, 97.5\%). Table II shows the chemotherapeutic regimens. All regimens include CDDP, which is categorized as HEC by the MASCC/ESMO antiemetic guidelines of 2016. Chemotherapeutic drugs were intravenously and intraarterially administered in 33 and 7 courses, respectively.

Palonosetron efficacy. For the primary endpoint, 83 (95.4\%) of the 87 courses achieved CR in the overall phase (within $120 \mathrm{~h}$ after palonosetron administration). CR was achieved in $86(98.9 \%)$ of the 87 courses during the acute phase and $84(96.6 \%)$ of the 87 courses during the delayed phase (Table III, Figure 1).

For the secondary endpoints, $67(77.0 \%)$ of the 87 courses achieved $\mathrm{CC}$ in the overall phase. $\mathrm{CC}$ was achieved in 84 
Table II. Chemotherapeutic regimens.

\begin{tabular}{lc}
\hline Anticancer drugs (doses) & Number of cases \\
\hline CDDP only $\left(60-80 \mathrm{mg} / \mathrm{m}^{2}\right)$ & Intravenous: 11 , Intraarterial: 2 \\
CDDP $(45-100 \mathrm{mg} /$ body $)+$ DOC $(45-80 \mathrm{mg} /$ body $)$ & Intravenous: 3, Intraarterial: 5 \\
CDDP $(50-80 \mathrm{mg} /$ body $)+$ DOC $(50-80 \mathrm{mg} /$ body $)+\mathrm{S}-1(100-120 \mathrm{mg} /$ day $)$ & Intravenous: 7 \\
CDDP $\left(80 \mathrm{mg} / \mathrm{m}^{2}\right)+5-\mathrm{FU}\left(800 \mathrm{mg} / \mathrm{m}^{2}\right)$ & Intravenous: 4 \\
CDDP $\left(70 \mathrm{mg} / \mathrm{m}^{2}\right)+$ DOC $\left(60 \mathrm{mg} / \mathrm{m}^{2}\right)+5$-FU $\left(750 \mathrm{mg} / \mathrm{m}^{2}\right)$ & Intravenous: 4 \\
CDDP $\left(80 \mathrm{mg} / \mathrm{m}^{2}\right)+5-\mathrm{FU}\left(800 \mathrm{mg} / \mathrm{m}^{2}\right)+\mathrm{Cmab}\left(250 \mathrm{mg} / \mathrm{m}^{2}\right)$ & Intravenous: 4 \\
\hline
\end{tabular}

CDDP: Cisplatin; DOC: Docetaxel ; 5-FU: 5-fluorouracil.

$(96.6 \%)$ of the 87 courses during the acute phase and 70 $(80.5 \%)$ of the 87 courses during the delayed phase (Table III, Figure 1). As nausea or vomiting occurred in 20 (23\%) courses, metoclopramide was administered as a rescue antiemetic drug.

\section{Discussion}

In cancer patients receiving chemotherapy, some of the biggest issues are adverse effects, such as nausea and vomiting. In patients with oral cancer, it is especially difficult to have a satisfying meal; furthermore, overlap nausea/vomiting, which result in double or triple stress, can seriously affect treatment compliance. Therefore, it is very important to take sufficient measures to prevent nausea and vomiting, not only in the acute phase but also in the late phase of chemotherapy administration.

Palonosetron is attracting attention because it has shown effectiveness in nausea and vomiting in both the acute and late periods, and is widely used overseas. Palonosetron is a second-generation $5-\mathrm{HT}_{3}$ antagonist that has a longer plasma-elimination half-life of $40 \mathrm{~h}$ and a 30-fold higher 5$\mathrm{HT}_{3}$ receptor binding affinity compared with first-generation $5-\mathrm{HT}_{3}$ antagonists, such as granisetron, ondansetron, and dolasetron (7). It was first approved in the United States in July 2003 as a novel $5-\mathrm{HT}_{3}$ receptor antagonist that showed a prophylactic effect on late-onset nausea and vomiting. Currently, it is approved in 63 countries, including the EU, Switzerland, and Austria. In Japan, the effectiveness of palonosetron was shown in a phase III test (PROTECT test) compared with granisetron for advanced emetogenic chemotherapy (8) to relieve gastrointestinal symptoms accompanying the administration of an antineoplastic agent (including late onset nausea and vomiting). Approval was obtained in January 2010. Furthermore, a pooled analysis of phase III clinical studies has shown that palonosetron was more effective than the older 5-HT3 antagonists for controlling CINV associated with moderately or highly emetogenic chemotherapy (9).
Table III. Number of courses achieving efficacy endpoints.

\begin{tabular}{lccc}
\hline & $\begin{array}{c}\text { Overall } \\
(0-120 \mathrm{~h})\end{array}$ & $\begin{array}{c}\text { Acute } \\
(0-24 \mathrm{~h})\end{array}$ & $\begin{array}{c}\text { Delayed } \\
(24-120 \mathrm{~h})\end{array}$ \\
\hline Complete response (\%) & $83 / 87$ & $86 / 87$ & $84 / 87$ \\
& $(95.4 \%)$ & $(98.9 \%)$ & $(96.6 \%)$ \\
Complete control (\%) & $67 / 87$ & $84 / 87$ & $70 / 87$ \\
& $(77.0 \%)$ & $(96.6 \%)$ & $(80.5 \%)$ \\
\hline
\end{tabular}

Complete response: No vomiting and no rescue medication; Complete control: no vomiting, no rescue medication, and no more than mild nausea.

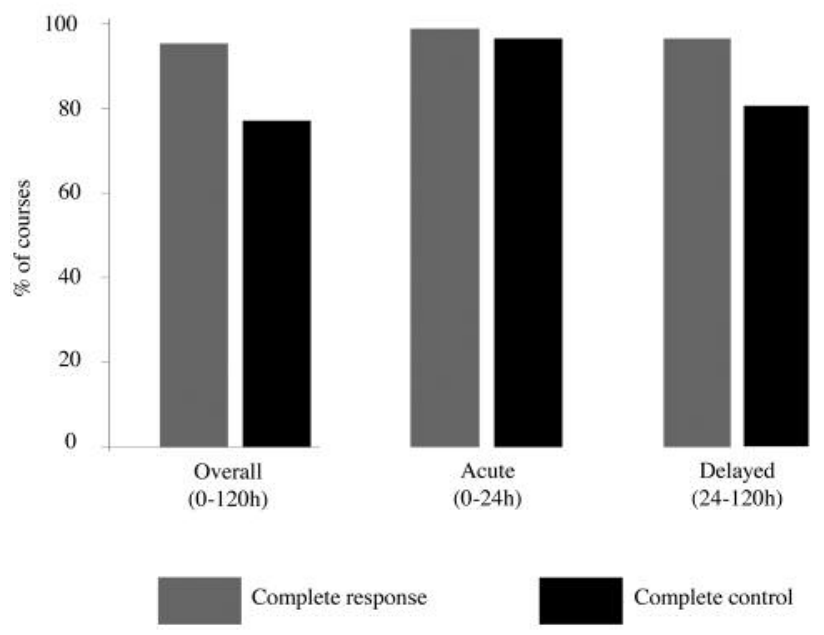

Figure 1. Percentage of courses with complete response and complete control.

The most noteworthy feature of palonosetron is that the receptor binding occupancy at $120 \mathrm{~h}$ after administration is approximately $70 \%$, and it can be expected to adequately control nausea and vomiting for the duration of the course 
with administration only on day 1 . It is considered that a single administration on day 1 is of great benefit in terms of cost, and reduction of the burden on patients and medical staff. In the antiemetic drug guidelines in Japan, a three-drug combination therapy of a $5-\mathrm{HT}_{3}$ receptor antagonist, dexamethasone, and aprepitant is recommended for CINV accompanying HEC; this is typically a regimen that includes CDDP (10). In particular, in the guidelines from the MASCC/ESMO, the only recommended $5-\mathrm{HT}_{3}$ receptor antagonist is palonosetron (4).

Although palonosetron is a very promising drug, there are currently few reports on chemotherapeutic regimens for oral cancers. Further, it is not sufficient to see how much effect can be expected for frequently used regimens. The treatment schedule of antiemetic drugs has not been established in combined chemo-radiotherapy for oral cancers, in which chemotherapeutic drugs are often administered intraarterially on a daily basis. Although daily administration of antiemetic drugs may result in overtreatment, there is no report about the effectiveness of palonosetron in various regimens targeting oral cancers.

In the present study, palonosetron was administered on day 1 only for every course in all facilities. To determine the palonosetron dose, we referred to 2 phase II studies in Japan, which examined the "dose-response relationship" for palonosetron doses of $0.075,0.25$, and $0.75 \mathrm{mg}$ in the delayed and overall phases of $\operatorname{CINV}(11,12)$. The results led to approval of a single $0.75 \mathrm{mg}$ palonosetron dose for the prevention of acute and delayed CINV in Japan. Therefore, we also adopted a dose of $0.75 \mathrm{mg}$ in the present study. As described in the results, we showed a high emetic suppression rate, not only in the acute phase but also in the delayed phase. It is noteworthy that, during the delayed phase, 84 of 87 courses $(96.6 \%)$ had CR, and 70 of 87 courses $(80.5 \%)$ had CC. However, in 60 of 87 courses, aprepitant and dexamethasone were also used in combination with palonosetron, as described in the Patients and Methods section. With the use of palonosetron alone, we speculate that such a high inhibition rate might not have been obtained.

Several studies have reported that the combination of a 5HT3 receptor antagonist with an NK-1 receptor inhibitor and dexamethasone is useful for the prevention of CINV induced by HEC $(13,14)$. Triple therapy consisting of palonosetron, aprepitant, and dexamethasone seems to be the strongest antiemetic treatment. Miura et al. reported the efficiency of triple treatment for HEC-induced CINV in lung-cancer patients, prevalence of CR and CC overall rate was 81.1 and $66.7 \%$, respectively (5). Compared with their report, our results showed a considerably high inhibition rate; the overall CR and CC rates were 95.4 and $77.0 \%$, respectively.

A limitation of the present study is that it was a singlearm study; therefore, we could not directly compare our results to those of other studies. However, our results indicate that antiemetic therapy, including palonosetron, can be beneficial in chemotherapeutic regimens for oral cancers.

In conclusion, palonosetron is effective at preventing HEC-induced CINV in patients with oral cancer, in both the acute and delayed phases. With a course of chemotherapy administered over 5 days, we have shown that a single dose of palonosetron resulted in sufficient suppression of CINV.

\section{Conflicts of Interest}

The Authors declare that they have no conflicts of interest.

\section{References}

1 Cancer statistics in Japan 2015 (2016). The Editorial Board of the Cancer Statistics in Japan. http://ganjoho.jp/en/professional/ statistics/brochure/2015_en.html [Last accessed October 15, 2017]

2 Genden EM, Ferlito A, Silver CE, Takes RP, Suárez C and Owen RP: Contemporary management of cancer of the oral cavity. Eur Arch Otorhinolaryngol 267: 1001-1017, 2010.

3 Karabajakian A, Toussaint P, Neidhardt EM, Paulus V, Saintigny $\mathrm{P}$ and Fayette J: Chemotherapy for recurrent/metastatic head and neck cancers. Anticancer Drugs 28: 357-361, 2017.

4 Roila F, Molassiotis A, Herrstedt J, Aapro M, Gralla RJ and Bruera E: 2016 MASCC and ESMO guideline update for the prevention of chemotherapy- and radiotherapy-induced nausea and vomiting and of nausea and vomiting in advanced cancer patients. Ann Oncol 27: v119-v133, 2016.

5 Miura S, Watanabe S, Sato K, Makino M, Kobayashi O and Miyao H: The efficacy of triplet antiemetic therapy with 0.75 $\mathrm{mg}$ of palonosetron for chemotherapy-induced nausea and vomiting in lung cancer patients receiving highly emetogenic chemotherapy. Support Care Cancer 21: 2575-2581, 2013.

6 Isoda A, Saito R, Komatsu F, Negishi Y, Oosawa N and Ishikawa T: Palonosetron, aprepitant, and dexamethasone for prevention of nausea and vomiting after high-dose melphalan in autologous transplantation for multiple myeloma: A phase II study. Int J Hematol Epub 105: 478-484, 2016.

7 Wong EH, Clark R, Leung E, Loury D, Bonhaus DW, Jakeman L, Parnes H, Whiting RL and Eglen RM: The interaction of RS 25259-197, a potent and selective antagonist, with 5-HT3 receptors, in vitro. Br J Pharmacol 114: 851-859, 1995.

8 Saito MI, Aogi K, Sekine I, Yoshizawa H, Yanagita Y and Sakai $\mathrm{H}$ : Palonosetron plus dexamethasone versus granisetron plus dexamethasone for prevention of nausea and vomiting during chemotherapy: a double-blind, double-dummy, randomised, comparative phase III trial. Lancet Oncol 10: 115-124, 2009.

9 Schwartzberg L, Barbour SY, Morrow GR, Ballinari G, Thorn MD and Cox D: Pooled analysis of phase III clinical studies of palonosetron versus ondansetron, dolasetron, and granisetron in the prevention of chemotherapy-induced nausea and vomiting (CINV). Support Care Cancer 22: 469-477, 2014.

10 Takeuchi H, Saeki T, Aiba K, Tamura K, Aogi K and Eguchi K: Japanese Society of Clinical Oncology clinical practice guidelines 2010 for antiemesis in oncology: executive summary. Int J Clin Oncol 21: 1-12, 2016. 
11 Maemondo M, Masuda N, Sekine I, Kubota K, Segawa Y and Shibuya M: A phase II study of palonosetron combined with dexamethasone to prevent nausea and vomiting induced by highly emetogenic chemotherapy. Ann Oncol 20: 1860-1866, 2009.

12 Segawa Y, Aogi K, Inoue K, Sano M, Sekine I and Tokuda Y: A phase II dose-ranging study of palonosetron in Japanese patients receiving moderately emetogenic chemotherapy, including anthracycline and cyclophosphamide-based chemotherapy. Ann Oncol 20: 1874-1880, 2009.

13 Miura S, Watanabe S, Sato K, Makino M, Kobayashi O and Miyao H: The efficacy of triplet antiemetic therapy with 0.75 $\mathrm{mg}$ of palonosetron for chemotherapy-induced nausea and vomiting in lung cancer patients receiving highly emetogenic chemotherapy. Support Care Cancer 21: 2575-2581, 2013.
14 Longo F, Mansueto G, Lapadula V, De Sanctis R, Quadrini S and Grande R: Palonosetron plus 3-day aprepitant and dexamethasone to prevent nausea and vomiting in patients receiving highly emetogenic chemotherapy. Support Care Cancer 19: 1159-1164, 2011.
Received September 18, 2017

Revised October 4, 2017

Accepted October 5, 2017 